\title{
Aplicação de Teorema de Ponto Fixo a um Modelo de Seleção de Carteiras de Investimento
}

\author{
Patricia Reis Martins* \\ Pós-Graduação em Ciências Computacionais, IME, UERJ, \\ 20550-013, Rio de Janeiro, RJ \\ E-mail: patriciarm75@yahoo.com.br
}

\author{
Carlos Frederico Vasconcellos Patrícia Nunes Silva \\ Departamento de Análise Matemática, IME, UERJ, \\ 20550-013, Rio de Janeiro, RJ \\ E-mail: cfredvasc@ime.uerj.br, nunes@ime.uerj.br
}

\section{RESUMO}

A seleção de carteiras de investimentos é considerada um dos principais problemas em finanças e está diretamente relacionada à Teoria Moderna de Portfólio, que envolve conceitos fundamentais como risco de ativos, retorno esperado de investimentos, correlação entre ativos e diversificação, que podem ser descritos através de conceitos da probabilidade e estatística. Uma solução para o problema de escolha de carteira de investimentos foi proposta por Harry Max Markowitz [4] em 1952, introduzindo a Teoria Moderna de Portfólio, e desde então é fonte de pesquisa e base de estudos em diversos trabalhos na área econômico-financeira.

A Teoria Moderna do Portfólio foi desenvolvida para dar apoio a decisões sobre a distribuição de recursos em carteiras de investimento de ativos financeiros, com o objetivo de definir, dado um conjunto de ativos, como estes devem fazer parte da carteira de investimentos. Isto é, em que proporção, $\alpha_{i}(i=1, \ldots, n)$, estes ativos devem ser ponderados, de forma a maximizar a utilidade esperada, alcançando assim a satisfação máxima do investidor relacionada ao retorno $\phi=\sum_{i=1}^{n} \alpha_{i} x_{i}$ da carteira de investimento.

Para Markowitz, a escolha da carteira está diretamente relacionada a dois fatores importantes: o risco e o retorno. O retorno esperado da carteira $E[\phi]$ é a média dos retornos esperados dos ativos e seu risco é mensurado pelo grau de volatilidade associado aos retornos esperados, ou seja, pela variância da carteira $\operatorname{var}[\phi]$. A escolha da carteira está na determinação do vetor $\vec{\alpha}$. Desta forma o retorno esperado da carteira de investimento será:

$$
E[\phi]=\sum_{i=1}^{n} \alpha_{i} E\left[x_{i}\right]=\alpha^{T} R .
$$

Markowitz definiu o risco de uma carteira de investimentos como sendo:

$$
\operatorname{var}[\phi]=\sum_{i=1}^{n} \sum_{j=1}^{n} \operatorname{cov}\left[x_{i}, x_{j}\right] \alpha_{i} \alpha_{j}=\alpha^{T} M_{2} \alpha
$$

onde $M_{2}=\left(\operatorname{cov}\left(x_{i}, x_{j}\right)\right)$ é a matriz de covariâncias entre os ativos, uma medida do grau de interdependência numérica entre as variáveis aleatórias.

Uma carteira de investimentos se apresenta bem equilibrada, quando é observada a diversificação, através da combinação de ativos que tendem a se mover em direções opostas, de tal forma que o risco global da carteira seja menor do que a soma dos riscos dos ativos isoladamente.

* discente do curso de Mestrado em Ciências Computacionais 
Supondo que o investidor busca maximizar o retorno de sua carteira a certo risco aceitável, ou minimizar o risco para um retorno desejado estabelecido, carteiras de investimento que apresentam este perfil são ditas carteiras eficientes.

Em Markowitz, o problema de seleção de carteiras de investimento é um problema de otimização quadrática que utiliza método de máximos e mínimos com restrições. Para o caso em que se deseja minimizar a variância da carteira de investimentos para um retorno desejado fixado, as restrições do problema serão: o retorno esperado da carteira fixado por um valor, e o somatório dos pesos de distribuição do investimento ser igual a 1.

De acordo com Athayde e Flores [1], desde Mandelbrot [3], os economistas sabem que a distribuição dos retornos de um ativo raramente segue o padrão de uma distribuição normal. A distribuição normal é inteiramente descrita por seus parâmetros de média e desvio padrão. Logo um modelo com base apenas em média e variância, pressupõe uma distribuição normal.

Desta forma, a abordagem de Markowitz para seleção de carteiras de investimento poderá não ter o alcance desejado. Sob essa perspectiva, o modelo de determinação de carteiras eficientes proposto por Athayde e Flores [1] incorpora momentos de ordem superior.

Com uma abordagem inovadora, Athayde e Flores apresentam uma nova perspectiva, incorporando ao modelo original a assimetria da carteira, o que torna os resultados mais consistentes. Ao considerar momentos de ordem superior, a utilidade esperada ainda é maximizada, incorporando agora o terceiro momento central, que corresponde à assimetria do retorno da carteira. Athayde e Flores [1] admitem que os momentos de ordem ímpar devem ser maximizados e os de ordem par, minimizados. O resultado de dualidade apresentado por Athayde e Flores [1] (Duality Lemma, p. 1338) garante que o problema de seleção de carteiras de investimentos para $n$ ativos de risco e um livre de risco é equivalente à determinação de um portifólio de variância mínima dados um retorno esperado $E\left(r_{p}\right)$ e uma assimetria $\sigma_{p^{3}}$. Tal portfólio é obtido pela minimização do Lagrangiano:

$$
\min _{\alpha} L=\alpha^{t} M_{2} \alpha+\lambda_{1}\left[E\left(r_{p}\right)-\left(\alpha^{t} M_{1}+\left(1-\alpha^{t} \mathbf{1}\right) r_{f}\right)\right]+\lambda_{2}\left(\sigma_{p^{3}}-\alpha^{t} M_{3}(\alpha \otimes \alpha)\right),
$$

onde $M_{1}, M_{2}$ e $M_{3}$ denotam as matrizes contendo os retornos médios, as covariâncias e as assimetrias dos $n$ ativos de risco e $r_{f}$ denota a taxa de retorno do ativo livre de risco. Além disso, 1 denota o vetor $n \times 1$ formado por 1's, $\alpha \in \mathbb{R}^{n}$ é o vetor de pesos para os ativos que compõem a carteira e $\otimes$ denota o produto de Kronecker.

Em [1], Athayde e Flores indicam que a solução do problema de seleção de carteiras eficientes pode ser modelada via um problema de ponto fixo. O objetivo central do nosso projeto de pesquisa é precisar matematicamente, com a utilização de análise convexa, o uso de teoremas de ponto fixo na solução do problema de maximização da utilidade esperada associado a modelos de seleção de carteiras eficientes. Analisamos matematicamente o modelo proposto por Athayde e Flores para determinar carteiras eficientes para $n$ ativos com risco e um livre de risco quando são considerados os três primeiros momentos.

Palavras-chave: Carteira de Investimento, Momentos de Ordem Superior, Ponto Fixo

\section{Referências}

[1] G.M. Athayde e R.G. Flores Jr., Finding a maximum skewness portfolio - a general solution to three-moments portfolio choice, Journal of Economic Dynamics and Control, 28 (2004) 13351352 .

[2] J.P. Aubin, "Optima and Equilibria: An Introduction to Nonlinear Analysis", Springer, 1998.

[3] B. Mandelbrot,The variation of certain speculative prices, Journal of Business 36 (1963) 394-419.

[4] H. Markowitz, Portfolio Selection, The Journal of Finance 7 (1952) 77-91. 